\title{
O Papel do Ciclo de Preços das Commodities no Desempenho Recente das Exportações Brasileiras
}

Daniela Prates*

Emerson Fernandes Marçal ${ }^{* *}$

Resumo: Este artigo tem como objetivo analisar o desempenho exportador brasileiro recente em termos de quantum e preço a luz de fatores tradicionais de demanda, como crescimento mundial e taxa de câmbio real. Após apresentar as principais características e determinantes da alta dos preços das commodities a partir de 2002 e do desempenho das exportações brasileiras após a adoção do regime de câmbio flutuante em 1999, o artigo, baseado num exercício econométrico, sugere que grande parte deste excelente desempenho pode ser atribuído a um movimento de alta de preços dos produtos exportados pelo país, que teve um efeito direito de aumento do valor exportado e indireto via aumento de quantum, ao tornar a remuneração dos exportadores mais atrativa. Estes efeitos são quantificados a partir da estimação de um modelo econométrico apropriado. Este modelo também identifica um componente cíclico importante nos movimentos de preços dos bens exportados pelo Brasil desde os anos 70 e indica que o movimento de alta recente está igualmente associado a uma trajetória cíclica dos preços.

Palavras-chave: Ciclo de Preços das Commodities, Exportações Brasileiras, Efeito-China, Conjuntura Macroeconômica Global.

Abstract: This paper aims to analyze the Brazilian export performance by the effects that traditional factor like world demand and real exchange rate have on quantum and prices of the exports. After analyzed the international commodities recent cycle and the performance of the Brazilian exports in the last years, the papers suggested, based on an econometric model, that most of the exceptional performance of this exports in the period of 2001-2006 was due to a huge rise in the prices of the products exported by Brazil. This rise had a direct effect on the value of the exports and an indirect effect on the quantum by making the export sector more profitable. The paper also suggests that most of the rise in Brazilian export products may be explained by a cyclical component in the prices

" Professora-Doutora do Instituto de Economia da Unicamp e pesquisadora do Centro de Estudos de Conjuntura e Política Econômica (Cecon). Pesquisadora do CNPq e da Fapesp. E-mail: daniprates@eco.unicamp.br

** Professor-Doutor do Instituto de Economia da Unicamp e pesquisadora do Centro de Estudos de Conjuntura e Política Econômica (Cecon). Pesquisador da Fapesp. E-mail: efmarcal@gmail.com

Recebido em 01 de julho de 2007. Aceito em 09 de janeiro de 2008.

$$
\text { Prates, D.; Marçal, E.F. OPapel do Ciclo de Preços das Commodities... }
$$


that has reached its maximum. There is evidence of an important cyclical component in the price of Brazilian exports.

Keywords: Commodities Cycle Prices, Brazilian Exports, 'China effect', Global Macroeconomic Scenario.

JEL Classification: F41; F47; C32; C51; C521.

\section{Introdução}

Em 2002, os preços de diversas commodities começaram a subir a partir de patamares historicamente baixos atingidos nos anos anteriores. Contudo, naquele ano, ainda não se vislumbrava a emergência de um período de alta consistente dos preços. Por um lado, o último período dessa natureza ocorrera há mais de 20 anos, na segunda metade dos anos 70 (interrompendo a relativa estabilidade posterior à guerra da Coréia de 1951/53). A partir de então, os preços das commodities apresentaram alta volatilidade, simultaneamente a uma tendência de queda, que se intensificou na segunda metade dos anos 1990. Neste período, os preços das commodities apresentaram deflação, decorrente do excesso de oferta em vários mercados, associado em parte aos avanços tecnológicos na agricultura e na extração de metais (IMF, 2006) - que induziu "liquidações", as quais deprimiram ainda mais os preços - como da queda da demanda dos países do leste e sudeste asiático após a crise de 1997/98. Por outro lado, a recuperação dos preços foi de início liderada, principalmente, por commodities agrícolas que enfrentaram choques de oferta de origem climática (com destaque para o El Nino). No caso dos preços das commodities metálicas, mais sensíveis às flutuações cíclicas da economia global (WTO, 2003), a alta foi tímida - devido à frustração das expectativas de uma retomada mais vigorosa do crescimento - e estes continuaram inferiores à média da década passada.

Entretanto, ao longo do segundo semestre de 2003, alguns analistas começaram a apostar na emergência de uma nova fase de elevação mais sustentável dos preços das commodities. A alta desses preços superou a previsão da Organização Mundial do Comércio (OMC) de um crescimento de 5,8\% em termos nominais (WTO, 2003). $\mathrm{E}$, enquanto o índice futuro da Reuters-CRB subiu 8,86\%, o índice spot subiu $16 \% .{ }^{1}$ Essa grande diferença entre as tendências das cotações

1 O Commoditie Research Bureau (CRB) calcula um índice geral com a cotação futura de 25 commodities, que é divulgado pela Agência Reuters. Esse instituto também calcula um índice spot, com as cotações à vista dessas mesmas commodities e vários sub-índices. 
futura e à vista revela que o próprio mercado não esperava uma alta sustentável. ${ }^{2}$

Uma característica fundamental da alta dos preços no período 2002 a 2006 (assim como o dos anos 70) foi sua abrangência: ela atingiu as mais diversas modalidades de commodities - energéticas (petróleo, essencialmente), metais não-preciosos, metais preciosos, grãos e óleos vegetais e alimentos -, cujos preços sofrem influência de diferentes fatores (caso, por exemplo, do impacto dos choques agrícolas sobre os preços dos alimentos). Contudo, a partir de abril de 2004, algumas dessas modalidades passaram a apresentar um desempenho divergente. Enquanto as cotações dos grãos e óleos e dos alimentos iniciaram um movimento baixista (associada a melhores condições nas lavouras e a fatores sazonais), as commodities metálicas e energéticas mantiveram sua trajetória ascendente, que persistiu em 2005 e nos primeiros meses de 2006. Ademais, o índice de commodities softs passou crescer, impulsionado pela alta das cotações do café (devido à quebra de safra no Vietnã, principal produtor) e, principalmente, do açúcar - decorrente do crescimento da demanda por fontes alternativas de energia, como o álcool etanol, diante dos altos preços do petróleo (IMF, 2006).

É possivel identificar dois principais determinantes desta trajetória altista: as condições macroeconômicas globais e o chamado efeitochina. Dentre estas condições, dois conjuntos de fatores, correlacionados, merecem destaque. Em primeiro lugar, a retomada do crescimento da economia global a partir de 2002: de uma taxa de crescimento de $2,6 \%$ em 2001, para 3,1\% em 2002, 4,1\% em 2003, $5,3 \%$ em 2004 e 4,8\% em 2005 (IMF, 2006). Se considerarmos a média anual do período 2002-2005, esta foi de 4,3\% (contra 3,6\% entre 1992 e 2000). O ritmo de crescimento da economia global tem influência fundamental sobre os preços das commodities. Os períodos de expansão são, em geral, acompanhados por alta dos preços relativos desses bens, ${ }^{3}$ enquanto os de retração são acompanhados por declínio desses preços. Isto porque as matérias-primas agrícolas e os metais são insumos da produção industrial, de oferta relativamente

2 A diferença entre os preços à vista e no mercado futuro é denominada de "base" ou "prêmio", sendo que uma base pequena indica que os dois preços caminham juntos e que as expectativas do mercado apontam para a manutenção da tendência dos preços no mercado à vista. Quando o mercado acredita que o movimento de alta vai continuar, os preços futuros são iguais ou mais altos que os preços à vista. Porém, períodos de variação da base são muito freqüentes e estão associados à dinâmica dos mercados futuros, altamente especulativa.

3 Preços das commodities deflacionados por um índice de preço de bens industriais dos países industriais. Ver: WTO (2003). 
rígida no curto prazo. ${ }^{4}$ Assim, apresentam em geral um comportamento pró-cíclico e constituem indicadores da recuperação industrial (WTO, 2003).

Em segundo lugar, a evolução e os patamares dos preços-chave da economia mundial - o preço do US\$ e a taxa de juros básica nesta moeda. A desvalorização do dólar em relação ao euro e ao iene até o primeiro semestre de 2005, ao resultar em preços mais baixos das commodities (cotados em dólar) para os países europeus e o Japão, estimulou a demanda por esses bens no contexto de recuperação do crescimento industrial (THE ECONOMIST, 2003 e MILLER e COY, 2004). De acordo com alguns analistas (BENTLEY, 2004a e 2004b), os investidores também adquiriram commodities no mercado futuro como uma alternativa de reserva de valor no período de depreciação do dólar. A partir de então, a incerteza em relação à taxa de câmbio da moeda-chave (dada a manutenção dos desequilíbrios globais) pode ter sustentado esse tipo de demanda (IMF, 2006). O contexto de taxas de juros historicamente baixas nos Estados Unidos e nos demais países centrais, também desempenhou um papel fundamental na alta recente dos preços das commodities: além de reduzir o custo de carregamento dos estoques de commodities, estimulando sua acumulação para fins produtivos, fomentou a formação de uma bolha especulativa no mercado futuro de commodities (THE ECONOMIST, 2003) - propício a esse tipo de fenômeno, dada sua alta liquidez -, a qual alimentou a alta dos preços à vista que, por sua vez, reforçou a alta dos preços futuros. ${ }^{5}$ Mesmo que as condições monetárias nos Estados Unidos não sejam mais tão favoráveis - dada a alta da taxa de juros básica (a Fed Fund Rate) desde meados de 2004 -, a política monetária na Europa e no Japão manteve-se frouxa desde então, contribuindo para sustentar a demanda especulativa por commodities. ${ }^{6}$

Já o chamado "efeito-China" refere-se ao excepcional crescimento

4 Contudo, são os preços das commodities metálicas que apresentam a maior correlação com a atividade industrial global. Isto porque, a oferta desses bens reage de forma muito mais lenta ao aumento da demanda, relativamente às commodities agrícolas. Nesse aspecto capacidade de ajuste da oferta decorrente das especificidades das condições de produção - o mercado de commodities metálicas se assemelha mais ao mercado de petróleo do que ao de matérias-primas agrícolas (IMF, 2006).

5 Esta bolha ancorou-se em compras por parte de hedge funds, aplicações especulativas nos fundos de commodities e aquisições estratégicas de fundos de investimento - associadas, num primeiro momento, à aposta na recuperação econômica global e, num segundo momento, à busca de diversificação dos portfólios e/ou de hedge contra a inflação, (IMF, 2006). Vale lembrar que esse contexto fomentou o surgimento de outras bolhas - no mercado imobiliário de vários países centrais e nos mercados de ativos dos países emergentes.

6 De acordo com previsões do Barclays Capital, o montante de recursos aplicados nos mercados. 
econômico deste país, que tem sido apontado como um dos principais determinantes da alta dos preços das commodities após 2002 (THE ECONOMIST, 2003; ROACH, 2004; IMF, 2004; THE ECONOMIST, 2004; Unctad, 2005). ${ }^{7}$ Esse crescimento, liderado por setores intensivos em commodities metálicas e industriais - automotivo, metalúrgico e de construção civil - pressionou a demanda por esses bens, ao mesmo tempo em que o crescimento populacional fomentou a compra externa de alimentos e demais commodities agrícolas. Em 2003, os números são surpreendentes: as importações chinesas cresceram $40 \%$ e foram responsáveis por $26,5 \%$ da demanda global de aço, $19,8 \%$ da de cobre e $19 \%$ da de alumínio (IMF, 2004). Além do crescimento econômico doméstico, o ingresso da China na OMC em dezembro deste ano - que implicou redução de tarifas e cotas de importações sobre esses bens - também contribuiu para o aumento das compras externas de commodities agrícolas e metálicas. Este ingresso constituiu, ao menos num primeiro momento, uma mudança estrutural, com impactos significativos sobre o comércio internacional (tanto de commodities quanto de bens industrializados), dado o peso deste país neste comércio: em 2001, a China era a sexta potência comercial, sendo responsável por $6,3 \%$ das exportações e 3,8\% das importações mundiais; já em 2003, esse último percentual passou para $5,5 \%$, tornando a China a terceira principal importadora mundial, posição mantida em 2004 e 2005 (WTO, 2005).

Esse contexto suscita várias questões imbricadas, dentre os quais: estamos presenciando mais um ciclo de preços das commodities, que se encontra na sua fase de alta, ou uma mudança estrutural nos preços relativos desses bens? Quais os impactos desta fase ascendente sobre os termos de troca dos países periféricos exportadores desses bens? ${ }^{7}$ Já este artigo pretende examinar o desempenho das exportações brasileiras no período 1999-2006, procurando detectar a

de commodities por parte de grandes fundos de investimento deve atingir US $\$ 110$ bilhões no final de 2006, contra US\$ 70 bi em 2005, US\$ 45 bi em 2004 e apenas US\$ 15 bi em 2003 (Dorsch, 2006). Todavia, o aumento da aversão ao risco em maio de 2006, associado às incertezas em relação à política monetária norte-americana, levou vários desses fundos a desmontarem suas posições nesses mercados, provocando forte volatilidade dos preços (www.valoronline.com.br).

7 Ademais, o crescimento de outros países asiáticos, como a Índia - e, mais recentemente, a recuperação econômica do Japão, segunda maior economia do mundo, altamente dependente de matérias-primas importadas - também tem elevado a demanda por commodities, contribuindo para a alta dos preços (Dorsch, 2006).

8 Dorsch (2006) examina a sustentabilidade da alta recente dos preços das commodities, a Unctad (2005) analisa os impactos da alta recente dos preços das commodities sobre os termos de troca dos países em desenvolvimento e Kaplinsky (2005) discute os efeitos dessa demanda sobre a tendência secular de deterioração dos termos de troca das commodities... 
influência neste desempenho da evolução dos preços das commodities (que respondem por mais de $40 \%$ dessas exportações). A seção 2 dedica-se a identificar as principais características e determinantes deste desempenho a partir da reelaboração dos dados primários divulgados pelo Ministério do Desenvolvimento da Indústria e do Comércio (MDIC) e pela Funcex. Na seção 3 e 4 são apresentados, respectivamente, o instrumental econométrico e os resultados do modelo utilizado. Na seção 5 são destacados os fatores explicativos do desempenho exportador recente apontados por este modelo. Seguem-se as considerações finais, nas quais se lançam algumas hipóteses sobre a sustentabilidade da alta recente dos preços das commodities.

\section{Evolução recente do desempenho exportador}

No período 2002-2006, a economia brasileira apresentou superávits crescentes na balança comercial, que garantiram resultados positivos nas transações correntes a partir de 2003. Nos dois primeiros anos após a mudança do regime cambial, em janeiro de 1999, a resposta das exportações e das importações à taxa de câmbio desvalorizada foi tímida. No biênio 2001-2002, o novo patamar da taxa de câmbio - resultado das desvalorizações de 1999, 2001 e 2002 (ver gráfico 1) - num contexto de desaceleração da demanda doméstica e do comércio mundial, surtiu efeitos mais expressivos sobre a balança comercial devido, sobretudo, à redução das importações. Já no período 2003-2005, as exportações iniciaram uma trajetória consistente de crescimento, associada tanto ao "choque externo benigno" - associado à alta dos preços das commodities, que possibilitou a melhora dos termos de troca da economia brasileira (ver gráfico 2), bem como ao crescimento da demanda externa - quanto à reação das exportações da manufaturados à taxa de câmbio mais competitiva (reação que normalmente ocorre após um lag temporal).

Assim, o co-movimento, mesmo que com alguma defasagem, en-

tre a taxa de câmbio real e o saldo comercial - previsto pela teoria econômica e observado por vários estudos empíricos ${ }^{9}$ - foi mais uma vez observado. Em 2002 e 2003, a taxa de crescimento desse saldo foi muito expressiva - respectivamente, 395\% e $88 \%$ - devido à contratação das importações no primeiro ano e ao forte crescimento

Jenkins e Edwards (2005) discutem os links entre a demanda chinesa, os preços das commodities e a redução da pobreza na Ásia e na América Latina.

9 Ver Holland, Xavier (2005); Marçal, Monteiro, Nishijima (2005). 

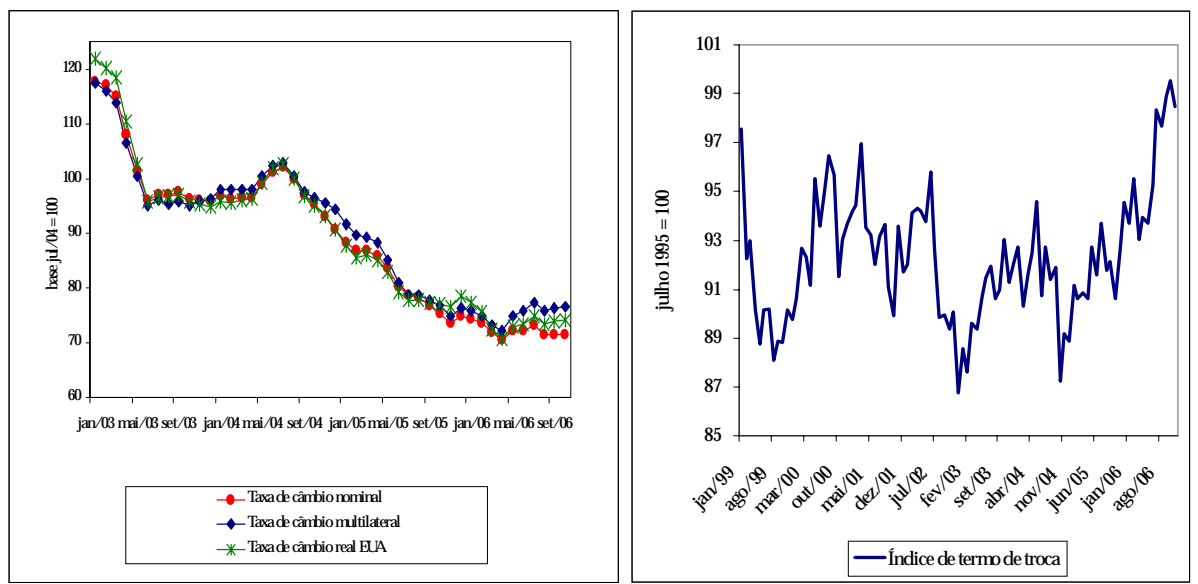

Gráfico 1. Taxas de câmbio nominal e real Gráfico 2. Termos de Troca Fonte: Banco Central e FMI. Elaboração pró- Fonte: Funcex. pria.

das exportações somado a uma recuperação tímida das compras externas no segundo ano. Já no biênio 2004-2005, o saldo cresce a taxas menos expressivas, mas ainda muito elevadas $-35,7 \%$ e $33 \%$, respectivamente - devido ao maior ritmo de expansão das exportações relativamente às importações. Somente em 2006, esse padrão se modifica - a taxa de crescimento das importações supera aquela das exportações (ver gráfico 3) -, mas não chega a comprometer o saldo comercial, como destacado no final desse item.

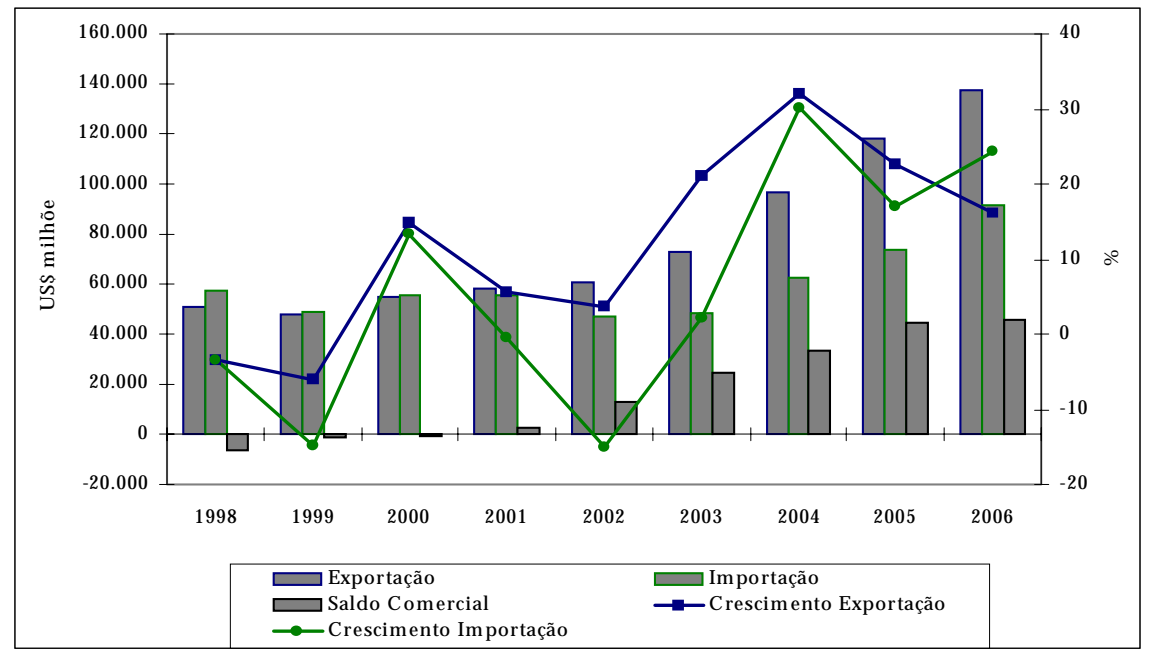

Gráfico 3. Valor e taxa de crescimento das exportações e importações Fonte: MDIC. Elaboração própria. 
A análise da pauta de exportação por classe de produto em termos de preço e quantum contribui para elucidar os determinantes da trajetória das vendas externas no período em questão, que teve uma influência fundamental na performance do saldo comercial. No período 1999-2002, enquanto o quantum expandiu-se, em resposta ao estímulo cambial, o comportamento dos preços foi desfavorável (ver Tabela 1), o que explica, em grande parte, a resposta lenta do saldo à taxa de câmbio depreciada. Chama a atenção a expressiva queda dos preços dos preços dos produtos básicos, que neutralizou em parte o forte crescimento do quantum (inclusive superior ao do período 2003-2005).

Tabela 1. Variação do valor, preço e quantum das exportações

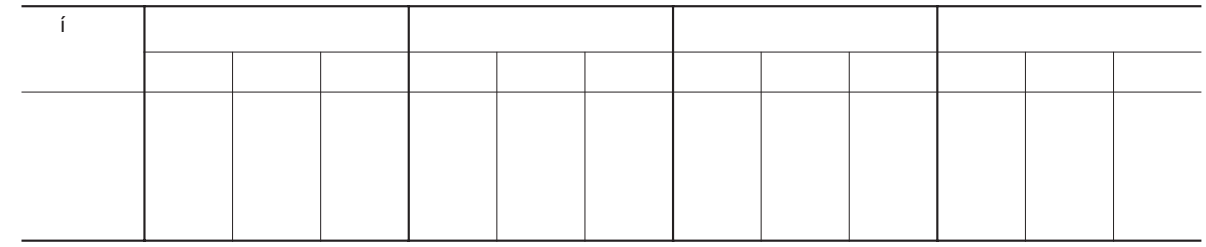

Fonte: Funcex. Elaboração própria.

Como ressaltam Markwald e Ribeiro (2005), o boom exportador desses produtos precedeu o período normalmente considerado pelos analistas (pós-2003) e não foi percebido com clareza devido a essa queda. Já nos semi-manufaturados e manufaturados, a expansão do quantum não foi tão expressiva, mas, em contrapartida, a variação negativa dos preços foi menor; o resultado líquido foi uma expansão menos intensa do valor, relativamente aos básicos. Em síntese, o pequeno crescimento do volume das vendas externas entre 1999 e 2002 decorreu da redução dos preços.

Já no triênio 2003-2005, a alta dos preços e, principalmente, do quantum contribuíram para a performance positiva das exportações brasileiras, que foram beneficiadas pelas duas dimensões do "choque externo benigno" já mencionadas acima: a alta dos preços e o crescimento da demanda externa. Considerando as três classes de produto, coerentemente com as características dos bens exportados, os básicos e semi-manufaturados se beneficiaram, especialmente, da dimensão "preço das commodities" - que resultou em altas expressivas dos preços das exportações -, apesar de também terem registrado taxas de crescimento consideráveis do quantum, impulsionadas, principalmente, pela demanda chinesa. Já no caso dos manufaturados a expansão do quantum foi mais expressiva, tanto em relação às demais classes de produto, como frente ao período anterior $(40 \%$ 
contra $26 \%$ entre 1999 e 2002) e constituiu o principal determinante do crescimento do seu valor. Assim, para essa classe de produto houve uma certa defasagem da reação das quantidades exportadas ao estímulo cambial de 1999 (ver Tabela 1).

Este comportamento diferenciado está associado às particularidades dos setores de bens manufaturados em relação à estrutura de mercado e à formação de preços. Como esses bens não são commodities e, assim, não têm preços fixados no mercado internacional (salvo algumas exceções), a concorrência via preço é importante, ao lado da diferenciação de produtos. Isto quer dizer que as sucessivas desvalorizações da moeda doméstica (1999, 2001 e 2002) significaram aumento da competitividade nesses setores, o qual surtiu efeito sobre o quantum exportado após um certo lag devido tanto aos maiores custos iniciais do redirecionamento das vendas para os mercados externos, como aos efeitos mais perversos da apreciação ininterrupta de taxa de câmbio real entre 1994 e 1998 sobre a sua competitividade.

As decisões estratégicas das empresas residentes, nacionais e estrangeiras, de direcionar para o exterior uma parcela relevante de sua produção de manufaturas surtiram efeito sobre o quantum, sobretudo, após 2002. Além daquelas desvalorizações, essas decisões também foram estimuladas pelo encolhimento do mercado doméstico, pela menor incidência de carga tributária sobre essas vendas relativamente às internas e pelo acesso a crédito externo mais barato (esse último, mais relevante no caso das nacionais) (BAER E CINTRA, 2004). ${ }^{10}$

As diferenças de competitividade internacional entre os vários setores da indústria de transformação contribuem para explicar o sucesso dessas estratégias exportadoras. Nassif e Puga (2004) analisam de forma detalhada a evolução do coeficiente de exportação da indústria de transformação brasileira, que passou de $14,7 \%$ em 1998 para $22,3 \%$ em 2003, sendo que ele aumentou na maioria dos setores, com reflexo de ganhos expressivos de competitividade (captados a partir do cálculo dos índices setoriais de vantagens comparativas reveladas entre 1996 e 2004). ${ }^{11}$ Os resultados mostram que,

${ }^{10}$ Apesar da instalação de novas firmas nesse período, atraídas pelo estímulo cambial, e da ampliação do número de empresas exportadoras, de acordo com o estudo de Marwald e Ribeiro (2005) as grandes empresas que já atuavam no comércio exterior (mesmo que marginalmente) foram responsáveis por $75 \%$ do crescimento das exportações no período 1998-2004

${ }^{11} \mathrm{O}$ Índice de Vantagens Comparativas Reveladas (VCR), utilizado como indicador de competitividade internacional, é calculado a partir da seguinte fórmula: VCR $=1000 / \mathrm{PIB}$ [(Xi-Mi) $((\mathrm{Xi}+\mathrm{Mi})(\mathrm{X}+\mathrm{M})) /(\mathrm{X}-\mathrm{M})]$, onde $\mathrm{X}$ e $\mathrm{M}$ são, respectivamente, exportações e importações... 
no âmbito dessa indústria, além da manutenção das vantagens comparativas nos setores onde a economia brasileira tem "competitividade estrutural" - como aqueles intensivos em trabalho e/ou em recursos naturais -, nesse período houve ganhos expressivos de competitividade nos setores de "veículos automotores", "aviação/ferroviário/embarcações/motos" - em função, sobretudo, do setor de aviação - e de "móveis".

No caso do agregado "aviação/ferroviário/embarcações/motos" (um setor de alta intensidade tecnológica), onde predomina o setor "aviação", seus ganhos de vantagem comparativa são dinâmicos e se ancoram no principal exemplo de inserção externa exitosa da indústria brasileira após a década de 1990, alcançada mediante o "fortalecimento do binômio empresa nacional (Embraer/fornecedores locais)/planejamento público (desenvolvimento tecnológico e financiamento)" (COUTINHO; HIRAKUTA; SABBATINI, 2003).

Já no setor de "veículos automotores" (de média intensidade tecnológica), dominado por Empresas Transnacionais (ETs), há fortes indícios de que essas empresas adotaram nesse período a estratégia de transformar suas filiais brasileiras em plataformas de exportação, não somente em âmbito regional (Mercosul), mas também global. Além dos ganhos de competitividade - associados às economias de escala e de escopo propiciadas pelo tamanho do mercado interno, bem como ao acordo automotivo vigente na década de 1990 - esta estratégia foi condicionada por fatores internos, em princípio conjunturais, como o encolhimento do mercado doméstico e a taxa de câmbio mais favorável após 1999. Como destacam Baer e Cintra (2004), este encolhimento estimulou as empresas do setor a buscarem ativamente o mercado externo - diante da elevada capacidade ociosa do período 2000-2002, que chegou a 53\% - e, simultaneamente, a procurarem novos mercados, dada a retração do mercado argentino. ${ }^{12}$ Ademais, a partir de 2003 as vendas dessa indústria também foram impulsionadas pelo acordo comercial com o

totais do país e Xi e Mi as exportações de cada setor. O primeiro membro entre colchetes corresponde ao saldo comercial efetivo por setor, enquanto o segundo ao saldo comercial neutro, ou seja, o saldo que ocorreria se a participação de cada produto no saldo comercial brasileiro fosse igual à sua participação na corrente de comércio do país. Se o sinal de VCR for positivo (negativo) o país tem vantagem (desvantagem) comparativa em determinado setor.

14 "Esse desempenho exportador mais relevante das indústrias localizadas no Brasil, principalmente montadoras, parece significar uma mudança estrutural no setor, porque para várias empresas a exportação passou a fazer parte da estratégia. Na medida em que as filiais brasileiras das empresas transnacionais se especializaram em alguns modelos e produtos, inclusive adaptando-os às condições de países em desenvolvimento, acabaram ocupando uma especialização na estratégia global dessas corporações" (BAER; CINTRA, 2004, p. 113). 
México, pela apreciação da moeda mexicana - que deteriorou a competitividade das exportações mexicanas de automóveis - e pelo crescimento da demanda da Argentina com a recuperação econômica após 2002. ${ }^{13}$ Contudo, a forte apreciação cambial após 2004 parece ter induzido a revisão de parte dessas estratégias, como destacado a seguir.

A reação mais expressiva do quantum exportado de bens manufaturados no período 2003-2005 também esteve diretamente associada à retomada do crescimento da economia internacional a partir de 2002, sob liderança dos Estados Unidos e dos países asiáticos, com destaque para a China. O "engate" do país no ciclo de expansão da economia e do comércio mundiais de 2003 a 2007 foi favorecido, por sua vez, pela diversificação geográfica das exportações brasileiras em direção aos mercados não-tradicionais, em curso desde $1998^{14}$ (ver Tabela 2). Assim, ao mesmo tempo em que os Estados Unidos continuam sendo um importante mercado de destino das nossas vendas externas, a China e os demais países da região ÁsiaPacífico, outro pólo neste ciclo, passam de uma participação de somente 5,1\% em 1998 para 10,2\% em 2006 nessa vendas (por sinal, a mesma tendência é observada para a América do Sul) ${ }^{15}$.

Assim, no período 2003-2006, a pauta exportadora brasileira, que se manteve concentrada em commodities primárias e bens de baixa intensidade tecnológica, revelou-se especialmente funcional dadas as características da expansão econômica da China, o patamar

${ }^{13}$ No segmento de "máquinas e tratores" (não contemplado no estudo de Nassif e Puga), também parece ter havido ganhos de vantagem comparativa. Segundo Baer e Cintra (2004), assim como no caso da indústria automobilística, nesse segmento a frustração em relação ao desempenho do mercado doméstico somada ao tamanho da demanda interna (que resultou em ganhos de escala e aumento da competitividade) induziram, igualmente, as ETs a concentrarem a produção para exportação no país mediante a transferência de linhas de produção de outros países. Este segmento, como o de "veículos automotores", também foi beneficiado por uma iniciativa de política industrial, o programa "Moderfrota". Ademais, nesses dois segmentos a existência de capacidade ociosa atuou como um importante indutor das vendas para o mercado externo. Sobre a relação entre capacidade ociosa, crescimento do quantum exportado e da produção, ver: Funcex (2005).

14 Como destacam Markwald e Ribeiro (2005), a diversificação geográfica das nossas exportações em direção aos mercados não-tradicionais contribuiu para sustentar o crescimento das nossas exportações no período 1999-2002, quando a demanda dos mercados tradicionais na América do Sul, principalmente da Argentina, e os preços das exportações retraíram.

15 O impacto das iniciativas de política externa do governo Lula - que procurou estreitar as relações do Brasil com os países latino-americanos e africanos - sobre a diversificação geográfica das nossas exportações é difícil de ser avaliado. Todavia, essas iniciativas podem ter tido algum efeito em termos de abertura de mercados nessas duas regiões. Sobre essa política, ver Almeida (2005). 
inusitadamente alto dos preços das commodities e a recuperação sincronizada da economia e do comércio mundial (resultando, inclusive, no aumento do market-share do país nas importações mundiais). ${ }^{16}$

Tabela 2. Mercado de destino das exportações

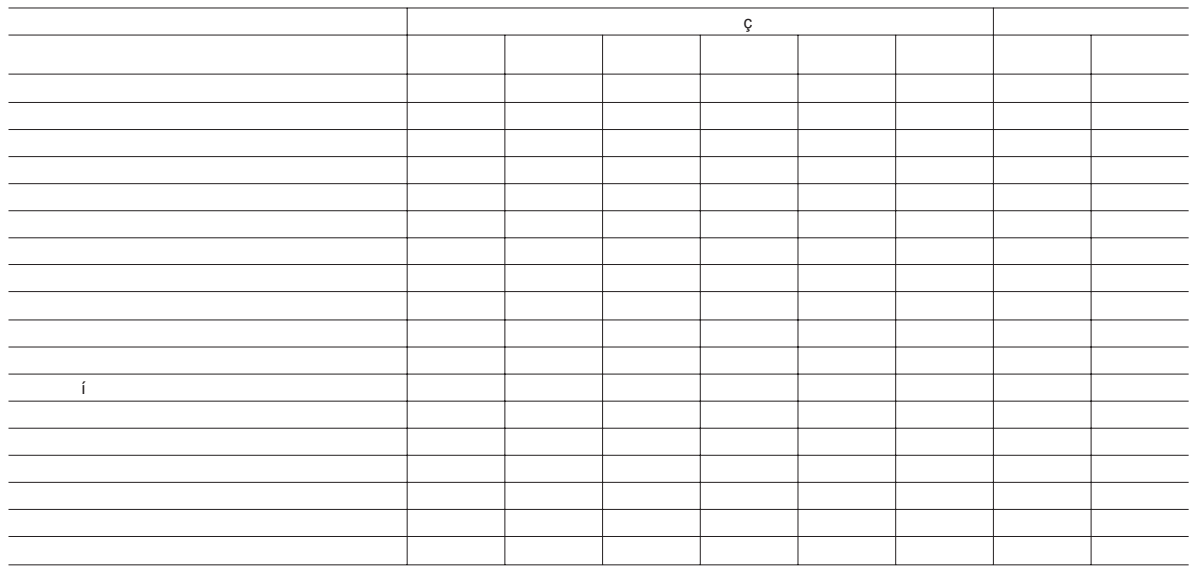

Fonte: MDIC. Elaboração própria.

Mesmo em 2005, após a forte apreciação cambial registrada em 2004 (ver gráfico 1), a taxa de crescimento das exportações continuou elevada e superior à das importações devido a uma conjunção de fatores. Em primeiro lugar, a alta dos preços no mercado internacional: em 2005, a contribuição da variação dos preços superou àquela do quantum no total das exportações e em todas as classes de produto, inclusive nos bens manufaturados (ver Tabela 1). Várias empresas do setor automobilístico e outros setores de manufaturados reajustaram seus preços no mercado externo, procurando compensar ou atenuar a perda de rentabilidade decorrente da evolução adversa da taxa de câmbio. Esta estratégia foi bemsucedida - no sentido de comprometer pouco o quantum exportado especialmente na América Latina, região que importa bens manufaturados de maior valor agregado, cujos produtores residentes, que operam em mercados oligopolizados, têm maior poder de formar preços. A estratégia de diferenciação desses bens por parte de algumas empresas parece também ter contribuído para o aumento dos

16 Segundo Markwald e Ribeiro (2005), o market-share do Brasil na importação mundial, que tinha declinado para 0,85\% em 1999, passou para 1,17\% em 2004. De acordo com dados da OMC, a participação do país nas exportações mundiais atingiu 1,1\% em 2005. 
preços. Ademais, vale mencionar que os preços dos bens manufaturados em geral cresceram em 2005, de acordo com os dados da OMC.

Em segundo lugar, a precedência dos contratos em relação aos embarques efetivos (de 6 a 12 meses, em média) e o fenômeno conhecido como "histerese de exportação" (associada à existência de capacidade instalada e demais custos envolvidos, como o risco de perda de mercados conquistados) sustentaram as quantidades exportadas. Em terceiro lugar, como destaca Negri (2005), várias firmas dos setores de média intensidade tecnológica conseguiram reduzir seus custos mediante a introdução de inovações tecnológicas nos processos produtivos, ${ }^{17}$ atenuando, assim, o impacto negativo da apreciação do real.

Em quarto lugar, o elevado diferencial entre os juros internos e externos. Esse diferencial, um dos determinantes centrais da tendência de apreciação da taxa de câmbio nominal desde 2004, permitiu a atenuação do impacto dessa tendência sobre a rentabilidade das exportações mediante dois mecanismos complementares de natureza financeira. Por um lado, as empresas exportadoras tiveram a opção de reduzir o custo financeiro mediante a realização de Adiantamentos de Contrato de Câmbio (ACCs). O aumento do diferencial entre a taxa embutida nesses contratos e aquela incidente sobre as linhas de capital de giro doméstica, somado à redução do spread cobrado pelos bancos, devido à intensificação da concorrência nesse segmento (LUCCHESI, 2005), tornou o custo financeiro dos ACCs ainda mais atrativo. A tendência de apreciação cambial também reduzia este custo, estimulando a contratação dessas linhas de crédito. Por outro lado, o diferencial de juros também induziu os exportadores a contratar ACCs e/ou antecipar a internalização das receitas em dólar com o objetivo de aplicar os recursos no mercado financeiro doméstico a uma taxa de juros real elevadíssima, ampliando as receitas efetivas em Reais.

Também é importante destacar que a redução da rentabilidade das exportações em decorrência da apreciação cambial variou setorialmente, em função, principalmente, de três fatores: do peso dos insumos importados; do grau de agregação de valor na produção; e da intensidade de capital (versus de mão-de-obra). Por exemplo,

17 Ademais, há indícios de que alguns setores manufaturados com maior poder de mercado (como a indústria automobilística) conseguiram manter sua lucratividade mediante a redução dos preços pagos por insumos e/ou componentes. Ou seja, nesse caso, os fornecedores arcaram com os custos da apreciação cambial por meio da compressão das suas margens de lucro. 
no setor farmacêutico, a valorização do Real reduziu o custo dos componentes importados; já a atual legislação de PIS/Cofins beneficiou os setores de baixo valor adicionado ${ }^{18}$ e o crescimento do salário em dólar (ou seja, a queda da relação câmbio/salário), somada aos menores ganhos de produtividade, penalizaram, sobretudo, os setores intensivos em trabalho, como têxteis e calçados. Todavia, os setores que tiveram menor perda de rentabilidade são exatamente aqueles que menos contribuem para o saldo comercial.

As altas de crescimento das vendas externas no período 20032005 se transmitiram ao saldo graças à expansão bem menos intensa das importações (como mencionado acima), associada ao baixo dinamismo do mercado interno e à substituição de produtos importados por nacionais no período precedente, induzida pela taxa de câmbio desfavorável às compras externas - processo que, devido aos custos envolvidos, também não é revertido rapidamente, em resposta à apreciação cambial.

Em 2006, todavia, os efeitos da apreciação cambial sobre o desempenho das exportações e importações começaram a transparecer. Este foi o primeiro ano, desde 2000, no qual a taxa de crescimento das compras externas superou aquela das vendas externas (ver gráfico 3). A perda de ritmo dessas vendas somente não foi maior devido ao comportamento favorável dos preços das commodities, que se manteve em 2006, pois a desaceleração do quantum exportado foi expressiva: uma expansão de somente $4 \%$ frente ao ano anterior, menos da metade da variação de 2005 (em relação à 2004) e da estimativa de expansão do volume do comércio mundial (de $8 \%$, segundo o FMI). A desaceleração do total do quantum exportado reflete, quase inteiramente, a redução da taxa de crescimento do volume de exportações de manufaturados (já que no caso dos básicos e dos semi-manufaturados a taxa de expansão desse quantum manteve-se praticamente constante em relação ao ano anterior). Essa queda constitui, por sua vez, a principal manifestação dos efeitos negativos da apreciação cambial sobre a competitividade das exportações.

A estratégia dos produtores de bens manufaturados de elevar os preços no mercado externo para contrabalançar esses efeitos foi

${ }^{18} \mathrm{O}$ PIS/Pasep e a Cofins eram cobrados com alíquota de 3,65\%, que incidia sobre a receita bruta. Com a mudança na legislação (do PIS/Pasep, pela lei n. 10.637 de 30/12/2002; e do Cofins pela Lei n. 10.833, de 29/12/ 2003), os tributos passaram a ser cobrados a 9,25\% sobre o valor adicionado na produção final. Se esse valor for relevante em relação ao custo dos insumos, o novo percentual superará a alíquota anterior, de 3,65\%. Assim, nos setores com alto conteúdo importado e baixo valor adicionado, a perda de rentabilidade foi atenuada tanto pela valorização do Real como pela mudança tributária. 
levada ao limite em 2006, se tornando cada vez mais ineficaz devido ao seu impacto contracionista sobre as quantidades exportadas. Assim, no caso desses bens, a alta dos preços e a queda do quantum são tendências estreitamente vinculadas e associadas à evolução da taxa de câmbio real no período imediatamente anterior. Vale destacar, todavia, que em alguns setores de maior conteúdo tecnológico, que exportam principalmente para os países da América Latina, o espaço para reajustes de preços foi maior, dadas as altas taxas de crescimento desses países, beneficiados igualmente pela conjuntura de alta de preços das commodities.

Finalmente, é importante mencionar que, ao lado do nível da taxa de câmbio real, a volatilidade da taxa de câmbio nominal também afeta negativamente as decisões de produção e investimento, principalmente naqueles setores de maior dinamismo no comércio mundial, nos quais o Brasil não tem competitividade estrutural e, assim, necessita constituir vantagens comparativas dinâmicas. É possível que no caso das decisões de investir, que envolvem custos elevados e irrecuperáveis, a volatilidade, ao implicar maior incerteza em relação à rentabilidade esperada do investimento, seja, inclusive, mais deletéria.

Há vários indícios de que a evolução recente das taxas de câmbio real e nominal já começou a surtir efeitos sobre essas decisões. ${ }^{19}$ Por exemplo, várias empresas exportadoras do setor de veículos automotores têm reavaliado suas estratégias, reduzindo as exportações locais e aumentando a produção e os investimentos em outros países (JURGENFELD, 2006). Além da busca de uma relação câmbio/salário mais favorável às exportações (devido ao patamar dos custos salariais mais baixos e/ou da taxa de câmbio), esses investimentos são estimulados pela própria valorização do Real, que torna os ativos externos mais baratos para os residentes (em 2006, os investimentos brasileiros no exterior superaram os investimentos diretos estrangeiros no país). ${ }^{20}$

\section{0 modelo econométrico}

Esta seção apresenta o modelo econométrico elaborado, que pretende estimar alguma relação que aproxime a evolução recente

19 Outros sintomas da perda de ímpeto das exportações desde 2005 são: a redução do número de empresas exportadoras, segundo informações da Associação Brasileira de Comércio Exterior; e o aumento da concentração das vendas externas num menor número de produtos, como mostra o estudo da Funcex a partir de três metodologias diferentes (FUNCEX, 2006).

${ }^{20}$ A valorização cambial também tem estimulado as remessas de lucros e dividendos pelas filiais das empresas transnacionais. 
das variáveis quantum e preço das exportações. No item 3.1, resumi-se o instrumento econométrico e nos itens 3.2 e 3.3 são descritos, respectivamente, os dados utilizados e os resultados obtidos

\subsection{Instrumental Econométrico}

Utiliza-se neste trabalho as técnicas de cointegração popularizadas por Johansen e Juselius numa série de trabalhos (Johansen, 1988, 1991, 1995 e Johansen $\mathcal{E}$ Juselius, 1990 e Juselius, 1995). Estas têm como ponto de partida um VAR irrestrito que pode ser reescrito em primeiras diferenças da forma dada abaixo:

eq. 1: $\Delta \mathbf{X}_{t}=\Gamma_{1} \Delta \mathbf{X}_{t-1}+\ldots+\Gamma_{p-1} \Delta \mathbf{X}_{t-p}+\Pi \mathbf{X}_{t-p} \Phi \mathbf{D}_{t}+\boldsymbol{\varepsilon}_{t}$ $\operatorname{com} \Gamma_{i}=-\left(\mathbf{I}-\Pi_{1}-\ldots-\Pi_{i}\right), i=1, \ldots, p-1$ e $\Pi=-\left(\mathbf{I}-\Pi_{1}-\ldots-\Pi_{p}\right)$

A análise do posto da matriz $\pi$ é essencial para avaliar a existência de cointegração. Se o posto da matriz for zero não haverá relações de cointegração. Se o posto for completo, todas as variáveis serão estacionárias. Se o posto for maior que zero e não completo haverá cointegração entre as variáveis.

A matriz $\pi=\alpha \beta$ ' pode ser decomposta em duas matrizes de posto cheio de tamanho pxr, p representando a dimensão do VAR e r, o posto da matriz $\mathrm{P}$. Testar hipóteses sobre os componentes dos vetores a e b em geral tem implicações importantes em termos econômicos. Supondo conhecido o posto da matriz $\pi$, o teste, de hipótese sobre os componentes dos vetores $\mathrm{a}$ e $\mathrm{b}$ pode ser feito mediante de testes de razão de verossimilhança com distribuição usual qui-quadrada. Maiores detalhes podem ser encontrados em Johansen (1995) e Doornik $\mathcal{E}$ Hendry (1997).

\subsection{Dados utilizados}

A Tabela 1 contém a descrição dos dados utilizados bem como as fontes nas quais os mesmos foram coletados. Na Figura 3 apresentam-se os gráficos das séries utilizadas. As séries que apresentam clara tendência de crescimento são quantum e produto americano. As demais parecem flutuar em torno de determinado patamar.

Tabela 1. Variáveis

\begin{tabular}{l|l|l}
\hline Variável & Sigla & Fonte \\
\hline Quantum Exportado & Q & FUNCEX \\
\hline Preço de Exportação & P & FUNCEX \\
\hline PIB americano & PIBUS & FMI
\end{tabular}




\begin{tabular}{l|l|l}
\hline IPCA & IPCA & IBGE \\
\hline Câmbio Nominal - R $\$ /$ US $\$$ & E & BACEN \\
\hline Logaritmo & L & - \\
\hline Primeira Diferença & D & - \\
\hline
\end{tabular}

\subsection{Resultados}

Optou-se por estimar um VAR como ponto de partida para aproximar o processo gerador dos dados. O objetivo consiste em estimar alguma relação que aproxime a evolução recente das variáveis quantum e preço das exportações. A inclusão das séries de PIB e câmbio efetivo - calculada deflacionado-se a série de câmbio nominal pelo índice de preços ao consumidor - justifica-se pelo fato da primeira estar relacionada a fatores de demanda das vendas externas e a segunda tanto a fatores de oferta quanto de demanda. A série de preços das exportações também é importante tanto para os demandantes dos produtos brasileiros quanto para os ofertantes nacionais, pois sua remuneração está ligada diretamente a esta variável.

Como bem discutido na literatura, o VAR pode ser visto como a forma reduzida de um modelo macroeconômico mais amplo e a recuperação das relações estruturais nem sempre é uma tarefa fácil. A compreensão mais precisa dos determinantes de tais regularidades exige um esforço de modelagem que ultrapassa os objetivos deste trabalho. Este artigo pretende tentar estimar algumas regularidades empíricas existentes. Os dados foram trabalhados em logaritmo, o que torna a forma funcional mais geral e permite a interpretação dos coeficientes como algo próximo ao conceito de elasticidade.

Estimou-se como primeiro passo um VAR irrestrito contendo as variáveis quantum exportado, preço, produto interno americano e câmbio efetivo em logaritmo, mais variáveis dummies para controlar a não normalidade no resíduo de algumas equações. Os testes de especificação são bons, com exceção da não normalidade nas equações do PIB americano e câmbio efetivo. Embora não sendo o resultado ideal, como estas equações devem fazer parte dos modelos marginais (hipótese testada e aceita - reportada mais à frente), a normalidade não deve ser vista como um problema que inviabilize a análise. Os resultados mostram que deve existir um vetor de cointegração por todos os critérios utilizados a pelos $5 \%$ de significância. 
Tabela 4. Teste de cointegração

\begin{tabular}{|l|l|l|l|l|l|l|l|l|}
\hline & & & & & & & & \\
\hline & & & & & & & & \\
\hline & & & & & & & & \\
\hline & & & & & & & & \\
\hline & & & & & & & & \\
\hline
\end{tabular}

VAR irrestrito: LQ, LP, LPIB_US, LEIPCA com 4 defasagens mais dummies.

Testou-se seguida se é possível obter algum tipo de condicionamento e, como sugerido no parágrafo acima, se pode condicionar as variáveis quantum e preço em câmbio efetivo e PIB americano. A estatística tem valor de 8,08 com distribuição qui-quadrada com dois graus de liberdade e p-valor de $1,76 \%$ (Tabela 3). ${ }^{21}$

Tabela 5. Testando exogeneidade fraca

\begin{tabular}{lllllll}
\hline Ho & $\mathrm{Q}$ & $\mathrm{P}$ & PIBUS & LEIPCA & $\begin{array}{l}\text { PIBUS, } \\
\text { LEIPCA }\end{array}$ & $\begin{array}{l}\text { PIBUS, } \\
\text { LEIPCA } \\
\text { LP }\end{array}$ \\
\hline $\begin{array}{l}\text { Estatística } \\
\text { de Teste }\end{array}$ & 16.888 & 3.8881 & 8.0151 & 0.24799 & 8.0818 & 14.844 \\
$\begin{array}{l}\text { Distribuição } \\
\text { p-valor }\end{array}$ & $\chi^{2}(1)$ & $\chi^{2}(1)$ & $\chi^{2}(1)$ & $\chi^{2}(1)$ & $\chi^{2}(2)$ & $\chi^{2}(3)$ \\
\hline
\end{tabular}

No teste para averiguar quais variáveis estão presentes no vetor de cointegração, apenas para a variável PIB americano não há evidências de que a mesma está presente no vetor de cointegração (Tabela 4). ${ }^{21}$

Tabela 6. Testando a exclusão de variáveis dos vetores de cointegração

\begin{tabular}{lllll}
\hline Ho & $\mathrm{Q}$ & $\mathrm{P}$ & PIBUS & LEIPCA \\
\hline $\begin{array}{l}\text { Estatística } \\
\text { de Teste }\end{array}$ & 21.044 & 10.966 & 5.7073 & 20.681 \\
$\begin{array}{l}\text { Distribuição } \\
\text { p-valor }\end{array}$ & $\chi^{2}(1)$ & $\chi^{2}(1)$ & $\chi^{2}(1)$ & $\chi^{2}(1)$ \\
\hline
\end{tabular}

${ }^{21}$ Ver: Johansen (1995) para uma descrição detalhada deste teste. 
Por fim, testa-se uma série de simplificações de forma conjunta para avaliar que tipo de relação de condicionamento existe e quais variáveis e que tipo de relações existem entre as variáveis que compõe o vetor de cointegração. A variável PIB americano pode ser excluída do vetor de cointegração e existe uma relação direta e proporcional entre quantum e preço exportado. Além disso, há exogeneidade fraca das variáveis PIB americano e câmbio efetivo com relação aos parâmetros de longo prazo. Todas estas hipóteses testadas conjuntamente têm distribuição qui-quadrada com cinco graus de liberdade e estatística igual a 10,77 e pvalor de 2,93\% (Tabela 7). ${ }^{21}$

Tabela 7. Testando Hipóteses Conjuntas sobre as cargas e o vetor de cointegração

\begin{tabular}{lll}
\hline Exogeneidade Fraca & PIBUS, & PIBUS, \\
& LEIPCA & LEIPCA \\
\hline $\begin{array}{l}\text { Exclusão da variável do vetor de cointegração } \\
\text { Homogeneidade }\end{array}$ & PIBUS & PIBUS \\
& & $\begin{array}{l}\text { Quantum, } \\
\text { Preços }\end{array}$ \\
\hline Estatística de Teste & & 10.771 \\
Distribuição & 9.0777 & $\chi^{2}(5)$ \\
p-valor & $\chi^{2}(4)$ & {$[0.0283]^{*}$} \\
\hline
\end{tabular}

O vetor de cointegração estimado e utilizado a partir de agora é dado abaixo:

eq. 2: $\mathrm{Cla}=+13.2259 *$ LQtot -13.2259 * LPtot -6.483 * LEIPCA -0.221413 * trend 0 ;

O mesmo vetor padronizado pode ser dado por:

eq. 3:CI2 = LQtot $-1 *$ LPtot $-0,490174582 *$ LEIPCA -0,016740865* trend 0 ;

Vale notar que as restrições impostas identificam o vetor de cointegração de forma exata.

Por fim, estimou-se o modelo condicional para as variáveis quantum e preço exportado. O sistema inicial tinha 58 parâmetros e o sistema final aceito após as simplificações têm 32 parâmetros no total. Os resultados das estatísticas que comparam o modelo geral (sem simplificações - SYS(28)) e o modelo simplificado (SYS(34)) são dados na Tabela 8. Os resultados mostram que as simplificações propostas são facilmente aceitas aos níveis de significância padrão. 
Tabela 8. Testes das simplificações proposta ao modelo condicional

\begin{tabular}{lccclccc}
\hline Modelo & T & P & & $\begin{array}{l}\text { log- } \\
\text { verossimilhança }\end{array}$ & SC & HQ & AIC \\
SYS(28) & 101 & 58 & OLS & 392.60 & -5.1241 & -6.0179 & -6.6258 \\
SYS(34) & 101 & 32 & OLS & 384.34 & -6.1485 & -6.6416 & -6.9770 \\
\hline
\end{tabular}

\begin{tabular}{|l|l|l|l|l|l|}
\hline \multicolumn{5}{|l|}{} \\
\hline & & & & & \\
\hline
\end{tabular}

A Tabela 9 apresenta-se os resultados da estimação da equação para a equação do quantum e preço do modelo condicional. Na Tabela 10 apresentam-se os resultados dos testes de especificação do modelo. Os resultados são muito bons. Não há evidência de não normalidade, autocorrelação ou heterocedasticidade nos resíduos das equações. Tanto o câmbio quanto o PIB americano tiveram os sinais esperados (positivo) na equação do quantum. Todavia, não fica claro se movimentos no câmbio efetivo geram efeitos nos preços de exportação dos produtos brasileiros.

Tabela 9. Equação do Quantum para o modelo condicional Amostra: 1980 (4) to 2005 (4)

\begin{tabular}{|c|c|c|c|c|c|}
\hline \multicolumn{6}{|c|}{ Equação: DLQtot } \\
\hline & Erro Padrão & $\mathrm{HCSE}$ & $\mathrm{t}-\mathrm{HCSE}$ & t-prob & \\
\hline Coeficiente & & & & & \\
\hline DLPtot_1 & 0.137259 & 0.2471 & 0.2503 & 0.548 & 0.585 \\
\hline DLQtot 2 & -0.170427 & 0.07572 & 0.07375 & -2.31 & 0.023 \\
\hline DLQtot_3 & -0.0827613 & 0.07461 & 0.08124 & -1.02 & 0.311 \\
\hline CIa_1 & -0.0308495 & 0.005013 & 0.004365 & -7.07 & 0.000 \\
\hline DLËIPCA & 0.136394 & 0.08837 & 0.09941 & 1.37 & 0.174 \\
\hline DLPIB_US_1 & 2.01805 & 1.077 & 0.9187 & 2.20 & 0.031 \\
\hline Constant & 0.277949 & 0.04506 & 0.04121 & 6.74 & 0.000 \\
\hline \multicolumn{6}{|c|}{ sigma $=0.0684774 \mathrm{RSS}=0.3985776442$} \\
\hline \multicolumn{6}{|c|}{ Equação: DLPtot } \\
\hline Coeficiente & Erro Padrão & HCSE & $\mathrm{t}-\mathrm{HCSE}$ & t-prob & \\
\hline DLPtot_1 & 0.286443 & 0.08363 & 0.08776 & 3.26 & 0.002 \\
\hline DLQtot_2 & -0.00707831 & 0.02563 & 0.03143 & -0.225 & 0.822 \\
\hline DLQtot_3 & -0.0622986 & 0.02525 & 0.04214 & -1.48 & 0.143 \\
\hline CIa_1 & 0.00852267 & 0.001697 & 0.001528 & 5.58 & 0.000 \\
\hline DLËIPCA & -0.0391663 & 0.02991 & 0.02820 & -1.39 & 0.168 \\
\hline DLPIB_US_1 & 0.628570 & 0.3646 & 0.3339 & 1.88 & 0.063 \\
\hline Constant & -0.0752895 & 0.01525 & 0.01435 & -5.25 & 0.000 \\
\hline
\end{tabular}


Tabela 10. Teste de especificação do modelo condicional

\begin{tabular}{|l|l|l|l|l|}
\hline DLQtot : & Portmanteau(11): & 10.8756 & & \\
DLPtot : & Portmanteau(11): & 6.26163 & & \\
DLQtot : & Teste AR 1-5: & $\mathrm{F}(5,80)=$ & 1.7780 & {$[0.1268]$} \\
DLPtot : & Teste AR 1-5: & $\mathrm{F}(5,80)=$ & 0.89788 & {$[0.4867]$} \\
DLQtot : & Normalidade: & $\chi^{2}(2)=$ & 3.5436 & {$[0.1700]$} \\
DLPtot : & Normalidade: & $\chi^{2}(2)=$ & 1.9892 & {$[0.3699]$} \\
DLQtot : & Teste ARCH: & $\mathrm{F}(4,77)=$ & 0.23098 & {$[0.9202]$} \\
DLPtot : & Teste ARCH: & $\mathrm{F}(4,77)=$ & 2.6201 & {$[0.0413]^{*}$} \\
DLQtot : & Teste hetero: & $\mathrm{F}(12,72)=$ & 0.50024 & {$[0.9079]$} \\
DLPtot : & Teste hetero: & $\mathrm{F}(12,72)=$ & 1.9743 & {$[0.0393]^{*}$} \\
DLQtot : & Teste hetero-X: & $\mathrm{F}(27,57)=$ & 0.72221 & {$[0.8210]$} \\
DLPtot : & Teste hetero-X: & $\mathrm{F}(27,57)=$ & 1.2972 & {$[0.2023]$} \\
Vetor & & & & \\
$\begin{array}{l}\text { Portmanteau(11): } \\
\text { Teste AR 1-5 no }\end{array}$ & $\mathrm{F}(20,148)=$ & 1.2558 & {$[0.2182]$} & \\
vetor: & & & \\
$\begin{array}{l}\text { Normalidade no } \\
\text { Vetor: }\end{array}$ & $\chi^{2}(4)=$ & 6.1105 & {$[0.1910]$} & \\
Teste hetero no & $\mathrm{F}(36,207)=$ & 1.0239 & {$[0.4394]$} & \\
vetor: & & & \\
Teste hetero-X & $\mathrm{F}(81,165)=$ & 0.79804 & {$[0.8719]$} & \\
no vetor: & & & \\
\hline
\end{tabular}

\section{Resultados econométricos e o desempenho exportador recente}

Um exercício simples baseado nos coeficientes do vetor de cointegração permite obter algumas considerações sobre o desempenho exportador recente. Supondo que a economia estivesse no seu equilíbrio de longo prazo em 2000 e que a evolução posterior pudesse ser explicada apenas pelo vetor de longo prazo, o seguinte exercício é possível. No período de 2000 a 2005 houve um crescimento médio anualizado do volume exportado de $16,5 \%$, sendo $12,4 \%$ efeito de quantum e o restante $3,6 \%$ de preço.

Pelo modelo estimado na seção anterior, o preço tem um efeito diretamente proporcional no quantum. Desta forma, dos 12,4\% de crescimento do quantum, cerca de $3,6 \%{ }^{22}$ ocorreram por conta do aumento de preços (ao tornar a remuneração dos exportadores mais atrativa), sendo o restante $-8,4 \%$ anualizado - decorrente de fatores extra-preço (dentre os quais o aumento da demanda externa, que foi significativo no período dado a recuperação da economia mundial, liderada pelos EUA e China, importantes parceiros comerciais do país). Considerando que o componente histórico responde por um crescimento anual de cerca $6,9 \%$ ao ano em média, o restante cerca de 1,3\% - poderia ser atribuído à taxa de câmbio. 
Se calcularmos a contribuição da taxa de câmbio, veremos que de fato esta deve ser negativa, pois houve valorização da moeda no período. Caso a hipótese de equilíbrio no ponto de partida seja mantida, tem-se que o quantum deve perder dinamismo no período subseqüente em termos de crescimento. Uma outra forma de acomodar tal diferença seria supor que havia um desajuste inicial no montante exatamente necessário para compensar o ajuste citado. Isto pode ser visto pela análise do ECM. A análise gráfica do ECM mostra, contudo, que este provavelmente não deve ser o caso e, assim, uma perda de desempenho do quantum é esperada por conta da valorização recente.

O modelo também chama a atenção para a insuficiência de fatores tradicionais na explicação do desempenho exportador brasileiro. $\mathrm{O}$ produto americano não foi capaz de explicar a tendência de crescimento do quantum exportado pelo Brasil. Este resultado foi obtido também num outro estudo brasileiro sobre o tema, mas aplicado ao saldo comercial (NISHIJIMA, 1998). Uma possível explicação para este resultado é a diversificação do destino das exportações brasileiras, destacada na seção 2, ou seja, esta variável (PIB americano) não é suficiente para representar os aspectos de demanda pelos produtos brasileiros. Outra hipótese é que predominam fatores de oferta na explicação da tendência de crescimento das exportações brasileiras. Mais pesquisa deve ser feita sobre o tema e talvez estudos que trabalhem com dados mais desagregados, setorialmente ou por destino, sejam capazes de jogar alguma luz para a baixa performance das variáveis tradicionais.

No que tange ao desempenho futuro das exportações brasileiras, este dependerá basicamente da evolução dos preços. Se os preços se mantiveram nos níveis atuais deve ocorrer uma perda de dinamismo suave das exportações, que devem convergir para seu desempenho histórico, pois a taxa de câmbio também não deverá fornecer estímulos positivos razoáveis, sendo o único termo dinâmico representado pela tendência histórica, estimada aqui na casa de $8,4 \%$ ao ano. Com alto grau de certeza, dificilmente o desempenho exportador recente, com taxas de crescimento em alguns anos acima de $20 \%$, se repetirá num futuro próximo.

O grande problema ocorrerá se os preços observados no período recente forem o pico de uma fase recente de alta (Figura 1) que se reverterá nos próximos anos. A análise visual do Gráfico da série indica quatro padrões de altas fortes seguidas de baixa forte. O primeiro foi de meados dos anos 70 a meados dos 80 , o segundo de meados dos anos 80 a meados dos 90, o terceiro de meados dos anos 90 a 2000

${ }^{22}$ Foi calculado o valor exato a partir das fórmulas padrão de matemática financeira. 
e o quarto, iniciado em 2001 cuja alta persiste até os dias de hoje. Se houver uma reversão e os níveis atuais de preços não forem sustentáveis, a taxa de crescimento das exportações poderia atingir patamares indesejavelmente baixos. A questão da sustentabilidade destes níveis é analisada a seguir, nas considerações finais.

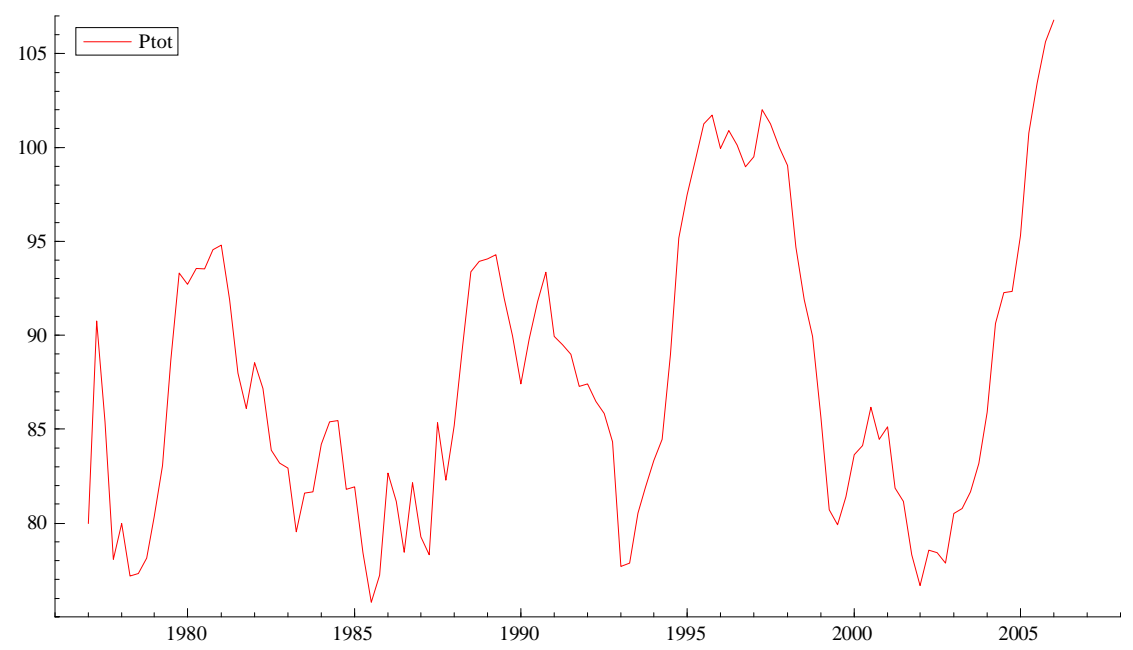

Figura 1. Evolução do índice de Preço das Exportações Brasileiras

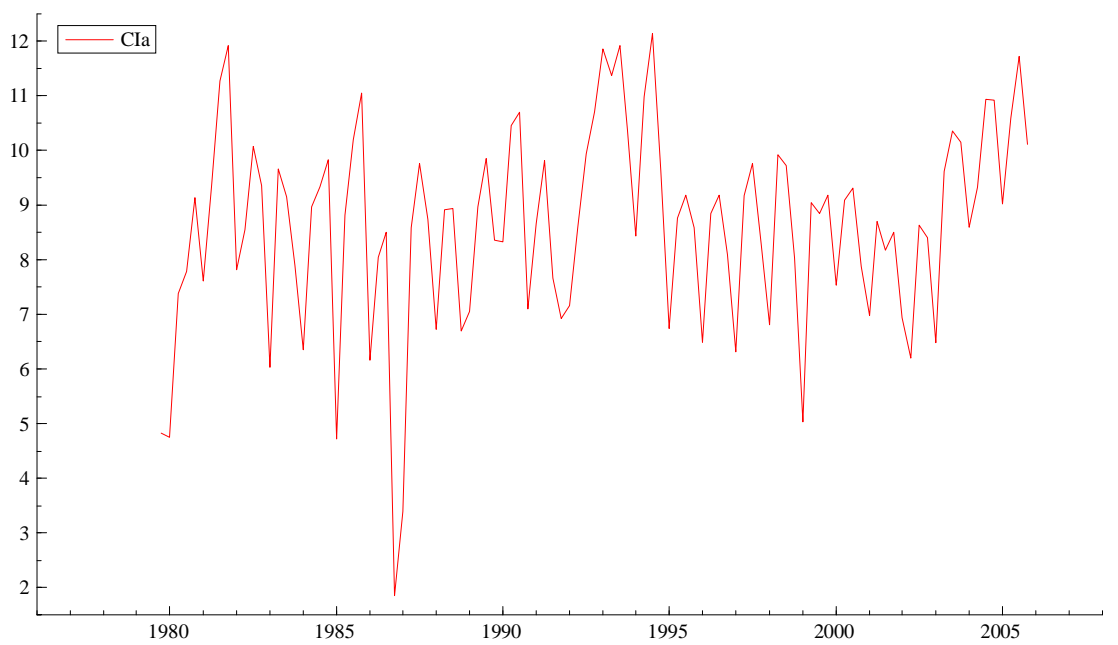

Figura 2. Evolução do Mecanismo de Correção de Erros Estimado 

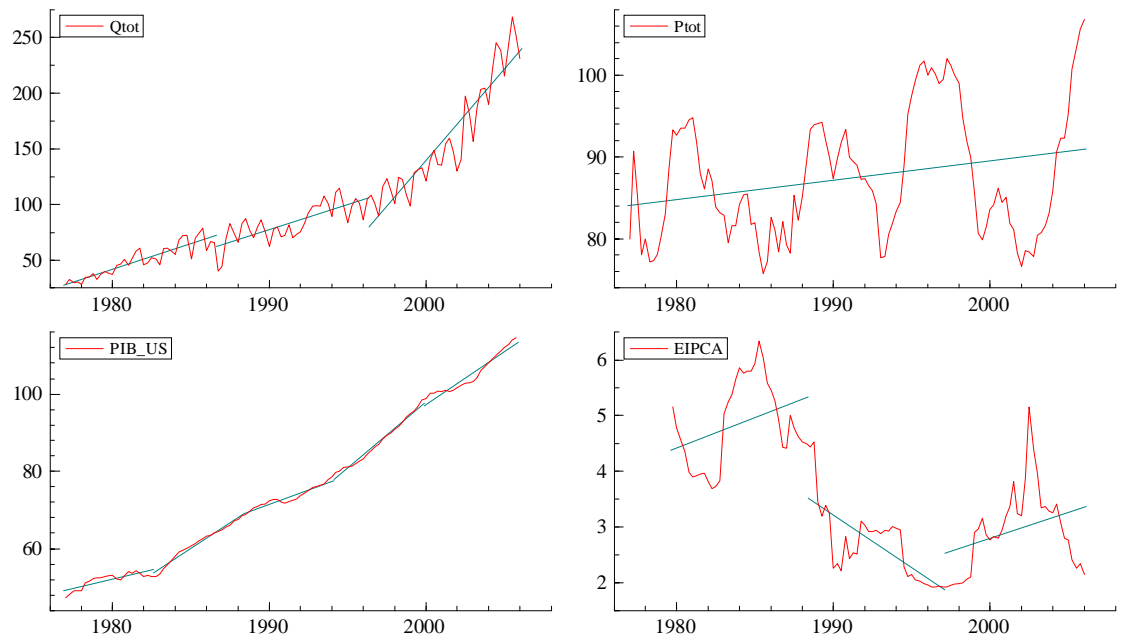

Figura 3. Gráfico das séries utilizadas no estudo econométrico

\section{Considerações finais}

Como destacado na Introdução, a alta dos preços das commodities no período 2002-2006, que contribuiu para desempenho favorável das exportações brasileiras nos últimos anos, esteve associada a uma sobreposição de fatores - recuperação econômica global; desvalorização do dólar; bolha especulativa fomentada pelas taxas de juros baixas; crescimento econômico da China - cuja importância relativa é de difícil dimensionamento. Ao que tudo indica, a singularidade da fase atual reside exatamente nessa sobreposição. Por exemplo, os impactos do aumento da demanda chinesa por commodities não teriam sido tão intensos numa situação de estagnação econômica global, da mesma forma que a emergência de uma bolha especulativa nos mercados futuros desses bens seria menos provável num contexto de taxas de juros básicas mais elevadas nos países centrais. Essa sobreposição de fatores - alguns de natureza mais estrutural, outros conjunturais - torna ainda mais difícil avaliar a sustentabilidade desta trajetória altista ou mesmo da manutenção dos preços das commodities nos patamares vigentes no início de 2006. Todavia, é possível levantar algumas hipóteses sobre a evolução dos principais condicionantes dessa trajetória: o efeito-china e as condições macroeconômicas globais. 
Como ressaltam o IMF (2004) e a Unctad (2005), apesar das taxas de crescimento da China e de seu comércio exterior serem parecidas com as observadas na maior parte dos países asiáticos (Japão e NICs) em etapas semelhantes de integração, a emergência e consolidação desse país como potência econômica em âmbito mundial provavelmente representará um "choque" muito mais expressivo sobre a oferta global de bens e fatores, com efeitos heterogêneos sobre os diferentes mercados e países. O estudo do IMF (2004) estima que esses impactos perdurarão até 2020. Ou seja, o efeito-China pode resultar numa mudança de patamar dos preços relativos de algumas commodities. Contudo, essa mudança não exclui a possibilidade de que esses preços retomem a tendência histórica de deterioração a partir de um patamar mais elevado.

Por um lado, é importante fazer algumas ressalvas sobre o impacto da integração comercial da China sobre o comércio internacional e, especificamente, sobre o mercado internacional de commodities: o impacto da liberalização comercial é, em grande parte, "once and for all", devendo se diluir no médio e longo prazo; o próprio processo de desenvolvimento resultará numa menor elasticidade-renda da demanda chinesa por esses bens; como advertido por vários analistas (como o Economist), os setores industriais chineses com excesso de capacidade e queda da eficiência do investimento são exatamente aqueles intensivos em commodities metálicas (metalurgia, automobilística, construção civil); finalmente, dada a concentração das compras externas de commodities nas filiais das empresas transnacionais instaladas neste país, pode-se deduzir que o boom de importações chinesas desses bens também está associado à recuperação econômica sincronizada dos países centrais e do sudeste asiático.

Por outro lado, dois dos fatores subjacentes à tendência histórica de deterioração dos termos de troca das commodities continuam presentes: o protecionismo agrícola nos países centrais e as diferenças nas elasticidades-renda da demanda por commodities e bens manufaturados. Enquanto são bastante incertos os desdobramentos da rodada atual da OMC (Rodada de Doha) em termos de redução desse protecionismo, diante dos conflitos de interesse envolvidos, o primeiro fator tem uma natureza estrutural (como mostrou Presbisch, 1949). Segundo a OMC, a tendência de declínio da participação dos setores extrativo e agrícola no comércio internacional persistiu nos últimos anos, a despeito da dimensão da demanda chinesa. Mesmo que a concentração da produção de várias commodities metálicas 
em poucos oligopólios aumente a capacidade de racionamento da sua oferta e atenue a queda dos preços num contexto de reversão cíclica da economia global, é pouco provável que ela seja capaz de compensar as demais tendências de longo prazo.

Em relação à conjuntura macroeconômica global, a sustentabilidade do cenário atual favorável, em termos de crescimento e inflação, é bastante incerta diante dos vários riscos envolvidos, com destaque para os desequilíbrios externos (déficit em transações correntes) e internos (bolha imobiliária) da economia norte-americana e seus desdobramentos sobre as taxas de juros (curta e longa) e a cotação do dólar. $\mathrm{Na}$ realidade, a própria alta dos preços das commodities constitui um desses riscos, devido aos seus potenciais efeitos inflacionários, os quais podem influenciar tanto a gestão da política monetária pelo Federal Reserve (Fed) como a evolução das taxas de juros de longo prazo. Uma alta mais rápida e intensa da taxa de juros básica americana pode induzir uma desova de estoques de commodities, com efeitos depressivos sobre os preços. Ademais, essa alta implicaria desaquecimento da economia americana, com efeitos negativos sobre o crescimento da China - dada a sua forte dependência das importações dos Estados Unidos - e, assim, sobre a demanda mundial de commodities. Mais uma vez, vale recorrer à história: a fase ascendente do ciclo dos anos 70 reverteu-se quando o choque de juros promovido pelo Fed em 1979 encareceu o custo de carregamento de estoques de commodities.

Mesmo que essa alta não se concretize, uma mudança súbita nas expectativas dos investidores - inerente à dinâmica dos mercados financeiros - pode desinflar a bolha de commodities, interrompendo o círculo vicioso de alta nos mercados futuro e à vista. Ademais, o estouro da bolha também pode ser provocado pela dinâmica dos mercados à vista: preços elevados tanto estimulam o aumento da produção quanto deprimem a demanda, o que pode resultar, num segundo momento, em deflação. Nas palavras da The Economist (2004b): "every bull market contains the seeds of its destruction". Por sinal, estes riscos se explicitaram em maio de 2006, quando as incertezas em relação à condução da política monetária americana desencadeou um movimento de realização de lucros nos mercados futuros de commodities (bem como em vários mercados de ativos emergentes).

A análise das seções 2 e 5 mostrou que a alta dos preços das commodities exportadas pelo país constitui um importante determinante da performance favorável das exportações nos últimos anos, tanto pelo seu impacto direto (efeito-preço), como pelo seu impac- 
to indireto sobre o quantum exportado. Se considerarmos o ano de 2005 e, principalmente, o primeiro semestre de 2006, a contribuição dos preços ao desempenho exportador foi mais acentuada do que na média do período 2003-2005: de acordo com a Funcex, no período janeiro-maio de 2006 , em relação ao mesmo período de 2005, o crescimento de $14 \%$ do valor das exportações decorreu da alta de $11 \%$ dos preços e de $3 \%$ do quantum; em termos de contribuição ao crescimento, os percentuais foram de $81 \%$ (preços) e $18 \%$ (quantum). Em suma, a vulnerabilidade deste desempenho a uma queda dos preços tornou-se especialmente elevada, num contexto de perda de dinamismo do quantum como reflexo da apreciação cambial excessiva entre meados de 2004 e o final de 2006.

\section{Referências}

BAER, M.; CINTRA, M. A. M. Brasil: investimento estrangeiro direto e estratégias empresariais. Santiago do Chile: Comissão Econômica para América Latina e Caribe (CEPAL), set. 2004.

BENTLEY, A. Commodity investor “wild" for weak dollar. Reuters, Feb. 18, $2004 a$.

. Weak dollar, China usher in new commodity heyday. Reuters, Mar. 18, $2004 \mathrm{~b}$. Disponível em: http://www.forbes.com/.

COUTINHO, L; HIRATUKA, C.; SABBATINI, R. O desafio da construção de uma inserção externa dinamizadora. Texto produzido para o Seminário Brasil em Desenvolvimento, UFRJ, Rio de Janeiro, set. 2003.

DOORNIK, J. A.; HENDRY, D. Modelling Dynamic System using PcFiml 9.0. London, 1997.

DORSCH, G. The 'commodity super cycle' - How long can it last? 2006. Disponível em: $<$ http://www.sirchartsalot.com>.

FERRAZ, G.; RIBEIRO, F. Desempenho exportador global e competição nos mercados da União Européia e dos Estados Unidos. Revista Brasileira de Comércio Exterior, ano XVIII, n. 80, p. 4-23, jul./set. 2004.

FUNCEX. Boletim de Comércio Exterior, ano X, n. 2, fev. 2006 . Boletim Setorial, ano IX, n. 2, jul./dez. 2005.

HOLLAND, M.; XAVIER, C. L. Dinâmica e competitividade setorial das exportações brasileiras: uma análise de painel para o período recente. Economia e Sociedade, v. 14, n. 1, p. 85-108, 2005;

(The) ECONOMIST. A copper-bottomed boom?, Oct. $2^{\text {nd }}, 2003$.

. The Hungry dragon. Feb. 19 th $2004 a$.

. The temperature is rising. Apr. $15^{\text {th }}, 2004 \mathrm{~b}$.

IMF. World Economic Outlook, Apr. 2006, chap. 1, apêndice 1.1. Washington D.C.: 
International Monetary Fund.

. World Economic Outlook, Apr. 2004, chap. 1, apêndice 1.1 e chp.2. Washington D.C.: International Monetary Fund.

JENKINS, R. and EDWARDS, C. How does China's growth affect poverty reduction in Asia and Latin America?, paper prepared for DFID, University of East Anglia, unpublished, 2005.

JOHANSEN, S. Estimation and Hypothesis Testing of Cointegration Vectors in Gaussian Vector Autoregressive Models, Econometrica, v. 59, n. 6, 1991.

. Identifying Restrictions of Linear Equations with Applications to Simultaneous equations and Cointegration, Journal of Econometrics, Elsevier Science, 69, 1995a.

Statistical Analysis of Cointegration Vectors, Journal of Economic Dynamics

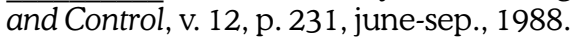

. Likelihood-based cointegrated vector auto-regressive models, Advanced Texts in Economics. New York: Oxford University Press, 1995b.

JOHANSEN, S.; K. JUSELIUS. Maximum likelihood estimation and inference on cointegration - with application to the demand for money, Oxford Bulletin of Economics and Statistics, v. 52, n. 3, 1990.

JURGENFELD, V. Câmbio faz fabricante produzir no exterior. Valor Econômico, 2 fev. 2006. p. B7

JUSELIUS, K. Do purchasing power parity and uncovered interest rate parity hold in the long run? An example of likelihood inference in a multivariate time-series model, Journal of Econometrics, v. 69, 1995.

LUCCHESI, C. P. Juros do crédito à exportação de curto prazo em recorde de baixa. Valor Econômico, 22 ago. 2005;

KAPLINSKY, R. Revisiting the revisited terms of trade: will china make a difference, Institute of Development Studies, March, unpublished, 2005.

MARÇAL, E. F.; MONTEIRO, W. O.; NISHIJIMA, M. Saldos comerciais e taxa de câmbio real: uma nova análise do caso brasileiro. In: Encontro Nacional de Economia, 33, 2005. Anais... Belo Horizonte: ANPEC - Associação Nacional dos Centros de Pósgraduação em Economia, 2005.

MARKWALD, R. Intensidade tecnológica e dinamismo das exportações. Revista Brasileira de Comércio Exterior, ano XVIII, n. 79, p. 3-11, abr.jun. 2004.

MARKWALD, R.; RIBEIRO, F. Análise das exportações brasileiras sob a ótica das empresas, produtos e mercados, Revista Brasileira de Comércio Exterior, n. 85, p. 3-20, 2005.

MILLER, R.; Coy, P. Prices: how high is up? Business Week, Mar. 8, 2004.

NASSIF, A.; PUGA, F. P. Estrutura e competitividade da industria brasileira: o que mudou? Rio de Janeiro: Bndes, 2004.

NEGRI, F. de. Padrões tecnológicos e de comércio exterior das firmas brasileiras. In: IPEA. Inovações, padrões tecnológicos e desempenho das firmas industriais brasileiras. Brasília: Instituto de Pesquisas Econômicas Aplicadas, 2005.

NISHIJIMA, M., Fluxos de Comércio no Brasil e seus Determinantes Básicos - Uma 
Análise de Cointegração. Dissertação de Mestrado, IE-UNICAMP, 1998.

PASTORE, A. C.; Blum, B. E Pinotti, M. C. Paridade de poder de compra, câmbio real e saldos comerciais, Revista Brasileira de Economia, v. 52, n. 3, 1998.

PREBISCH, R. El desarrollo económico de la América Latina y algunos de sus principales problemas. In: Gurrieri, A. La obra de Prebisch en la Cepal. México: Fondo de Cultura Económica, 1982, p. 99-155. Primeira edição: 1949

PUGA, F. P. A inserção do Brasil no comércio mundial: o efeito china e potenciais de especialização das exportações. Rio de Janeiro: Banco Nacional de Desenvolvimento Econômico e Social, out. 2005. (Texto para Discussão, n. 106).

ROACH, Stephen. Global: shades of 1994. Morgan Stanley. Global Economic Forum, Apr. 12, 2004. http:/www.morganstanley.com/GEFdata/digest/20040412-mon.html.

SARTI, F.; SABATINI, R. Conteúdo tecnológico do comércio exterior brasileiros. Campinas: Unicamp. Instituto de Economia, 2003. (Trabalho não publicado).

UNCTAD. Trade and Development Report. Geneve: United Nations on Trade and Development, 2005 (chp. 3). Development, 2002.

WTR. World Trade Statistics. Geneve: World Trade Organization, 2005. . World Trade Report. Geneve: World Trade Organization, 2003. 
